\title{
Adjacent Level Vertebral Fractures in Patients Operated with Percutaneous Vertebroplasty
}

\author{
Dangol Bijendra, Xiaotao Wu*, Zanli Jiang, Lei Zhu, Maharjan Promish, Singh Ratish \\ Department of Spine Surgery, Zhongda Hospital Affiliated to Southeast University, Nanjing, China \\ Email: *wuxiaotaospine@seu.edu.cn
}

How to cite this paper: Bijendra, D., Wu, X.T., Jiang, Z.L., Zhu, L., Promish, M. and Ratish, S. (2018) Adjacent Level Vertebral Fractures in Patients Operated with Percutaneous Vertebroplasty. Open Journal of Orthopedics, 8, 116-126.

https://doi.org/10.4236/ojo.2018.83014

Received: February 2, 2018

Accepted: March 16, 2018

Published: March 19, 2018

Copyright $\odot 2018$ by authors and Scientific Research Publishing Inc. This work is licensed under the Creative Commons Attribution International License (CC BY 4.0).

http://creativecommons.org/licenses/by/4.0/

\begin{abstract}
Percutaneous vertebroplasty is a minimally invasive procedure that involves filling of a fractured vertebral body with bone cement to relieve pain and to restore the vertebral height. It is a safe and effective treatment and is widely used for treating Osteoporotic Vertebral Compression Fracture. Despite of its beneficial advantages over primary conservative managements, adjacent level vertebral compression fracture remains the challenge for surgeons. Adjacent level vertebral compression fracture following percutaneous vertebroplasty using PMMA cement has been reported as a complication. Numerous risk factors have been reported for the occurrence of new adjacent VCFs after PVP. The multiple level osteoporotic vertebral compression fractures and the increasing age of the patients are directly proportional to the risk of developing new symptomatic adjacent vertebral compression fracture after PVP. Moreover, low BMD and cement leakage are other factors that directly affect the incidence of new symptomatic adjacent vertebral fractures. The aim of this review is to evaluate the adjacent level vertebral compression fracture following percutaneous vertebroplasty on the basis of radiographs, Kaplan-Meier Estimation index and also the factors that lead to adjacent level vertebral compression fractures.
\end{abstract}

\section{Keywords}

Osteoporosis, Osteoporotic Vertebral Compression Fracture, Percutaneous Vertebroplasty, Polymethylmethacrylate, Kaplan-Meier Estimation

\section{Introduction}

\subsection{Osteoporosis}

Osteoporosis is defined as a skeletal disease condition characterized by low bone mass which precipitates the fracture risk [1]. Bone density decreases after me- 
nopause due to decreased levels of estrogen hormone. Osteoporosis may also occur due to number of diseases or treatments like alcoholism, anorexia, hyperthyroidism, renal diseases. Anti-seizure medications, chemotherapy, proton pump inhibitors, selective serotonin reuptake inhibitors and glucocorticoids also increase the risk of developing osteoporosis. Lack of exercises and smoking are also risk factors [2]. Osteoporosis is defined as a bone density of 2.5 standard derivatives below that of a young adult. This is typically measured by dual energy $\mathrm{x}$-ray absorptiometry (DEXA) scan [3]. The commonest fragility fracture due to osteoporosis is vertebral compression fractures (Figure 1) affecting $25 \%$ of post menopausal women and more than 200 million individually worldwide [4]. Despite proper conservative treatment, some patients continue to develop severe pain, vertebral compression and kyphotic deformity [5]. Nowadays, OVCF are being increasingly treated with minimally invasive bone augmentation technique like Percutaneous Vertebroplasty.

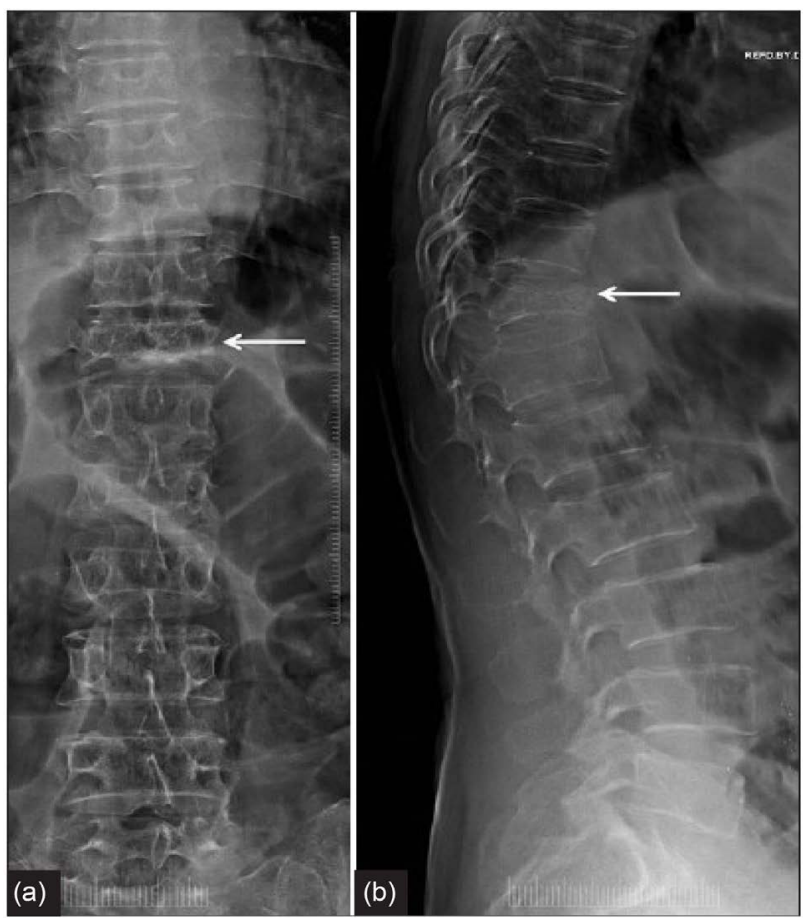

Figure 1. Radiograph of thoracic vertebra T12 showing compression vertebral fracture X-ray AP (a) and Lateral view (b).

\subsection{Relevant Anatomy}

The thoracic spine is typically made up of 12 vertebrae. These vertebrae have a body, pedicles, laminae, spinous processes, and facet joints (Figure 2). Additionally, they have prominent lateral processes that form the articulation with the paired 12 ribs on either side. The 12 vertebrae, 24 ribs, and sternum together form the chest cavity, allowing negative-pressure respiration and providing protection of the chest wall. The thoracic spine is highly immobile [6].

The lumbar spine is the next mobile segment of the spine, typically consisting 
of 5 large vertebrae with classic features, including body, pedicles, lamina, spinous processes, facet joints, and lateral processes (Figure 3). The lumbar spine is mobile with all articulations, contributing to flexion-extension, bending, and rotation. The lumbar spine allows truncal mobility [6].

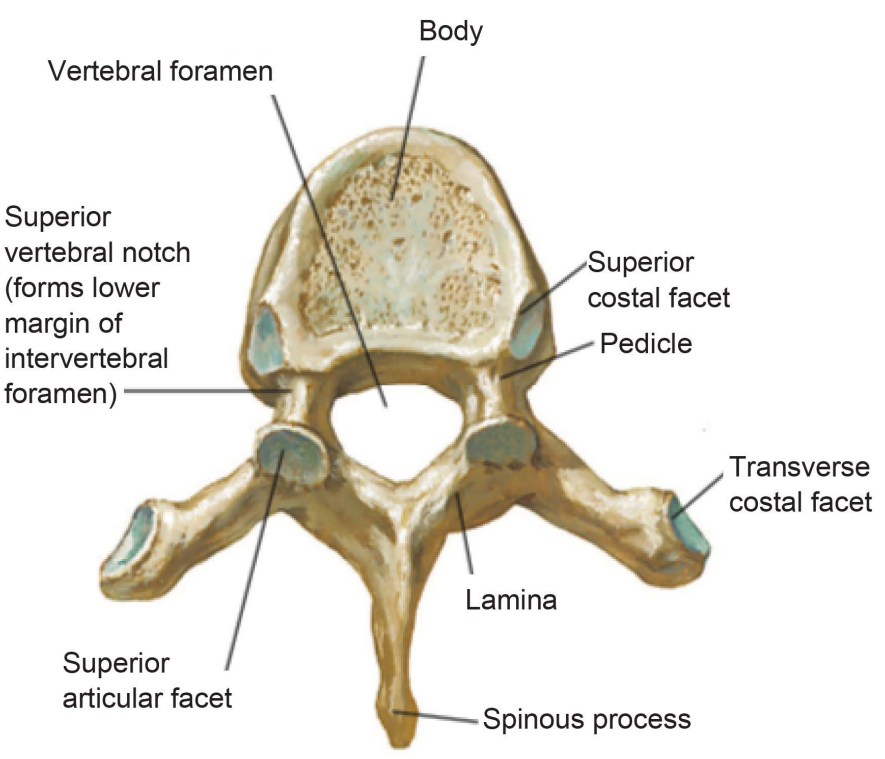

T6 vertebra: superior view

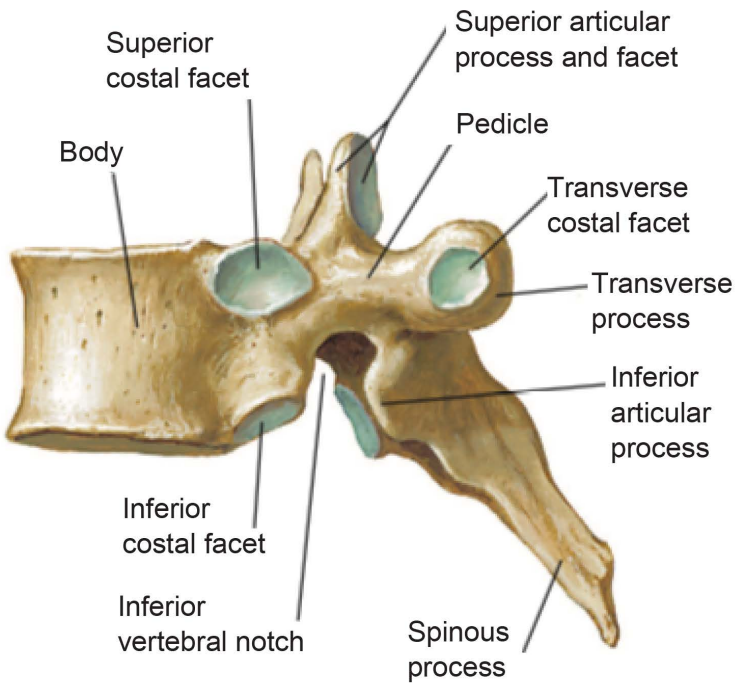

T6 vertebra:

lateral view

Figure 2. Illustration of thoracic vertebrae showing vertebral body, pedicles, facets, transverse process, rib joints, spinous process, and lamina [7].

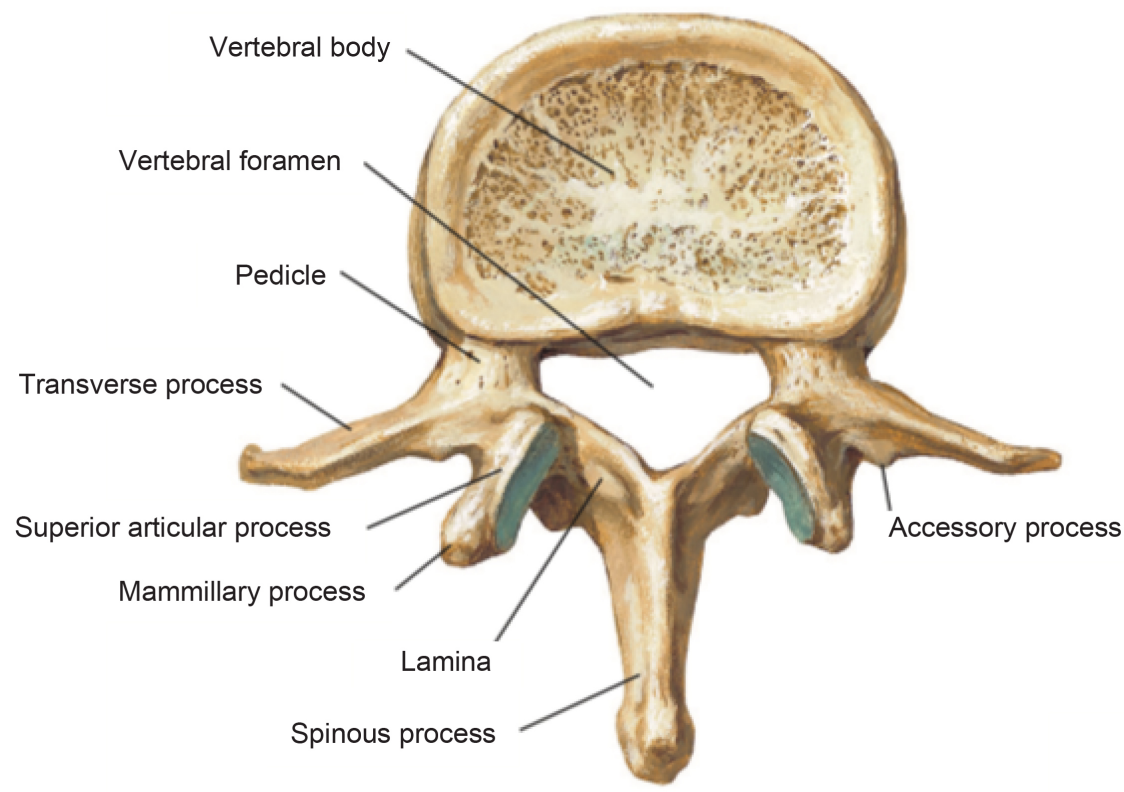

L2 vertebra:

Figure 3. Illustration of lumbar vertebrae showing vertebral body, pedicles, facets, transverse process, spinous process, and lamina [7]. 


\subsection{Percutaneous Vertebroplasty (PVP)}

Percutaneous vertebroplasty is a safe and efficient procedure for treating osteoporotic vertebral compression fractures [8]. Percutaneous vertebroplasty is one of the widely accepted treatments for VCFs of various causes. These procedures are associated with a decrease in the morbidity rates after VCFs. However, complications also have been reported [9]. Vertebroplasty is a minimally invasive, image-guided therapy used to relieve pain from a vertebral body fracture. It has been used for osteoporotic or malignant fractures. Initially, the major indication was treatment of spinal hemangiomas, as described in 1987 by Galibert et al. [10]. Vertebroplasty can increase patient mobility, decrease narcotic needs, and prevent further vertebral collapse. Percutaneous vertebroplasty (PVP) usually involves percutaneous injection of a cement, polymethylmethacrylate (PMMA), into the vertebral bodies [6].

Table 1. Indication and contraindication of PVP.

\begin{tabular}{lll}
\hline \multicolumn{1}{c}{ INDICATIONS } & \multicolumn{1}{c}{ CONTRAINDICATIONS } \\
\hline $\begin{array}{l}\text { Painful Osteoporotic vertebral } \\
\text { compression fractures }\end{array}$ & - & Asymptomatic fractures. \\
- Spinal Tumors & - & $\begin{array}{l}\text { Active osteomyelitis of the fractured vertebra, Un- } \\
\text { correctable coagulopathy. }\end{array}$ \\
Vertebral Hemangiomas & $-\begin{array}{l}\text { Allergy to vertebroplasty cement or } \\
\text { opacifying agents. }\end{array}$ \\
& - & $\begin{array}{l}\text { Significant central canal narrowing from } \\
\text { retropulsion of bony fragment or epidural } \\
\text { tumor, Ongoing systemic infection, } \\
\text { Myelopathy or radiculopathy from fracture level. }\end{array}$ \\
&
\end{tabular}

The indications and contraindications of PVP are listed as above in Table 1. The common indications for PVP are painful OVCF [6], Spinal tumors [11] and vertebral hemangiomas [12]. Although PVP is a safe and efficient procedure for treating OVCF, it has some limitations PVP in contraindicated in cases like asymptomatic vertebral fractures, active osteomyelitis of vertebra, coagulopathies, allergy to the cement used, Significant central canal narrowing and epidural tumors [13].

\subsection{Technique of Percutaneous Vertebroplasty}

- After obtaining informed consent, the patients were placed in the prone position at operating table (Figure 4(a)).

- Under aseptic precautions, the skin and paravertebral soft tissues were anesthetized with $1 \%$ lidocaine.

- The pedicle of fractured vertebra is localized using biplanar fluoroscopy (Figure 4(b)).

- 11 guaze needle for L-spine or 13 guaze needle for T-spine were inserted at the anterior and middle one third region of the fractured vertebral body (Figure 4(c)). 
- Polymethylmethacrylate (PMMA) mixed with barium was then injected into the vertebral body under fluoroscopic guidance.

- Cement injection is stopped when the posterior one fourth of the vertebra is filled or if any signs of leakage are seen (Figure 5).

- Wound cleaned and aseptic dressing applied.

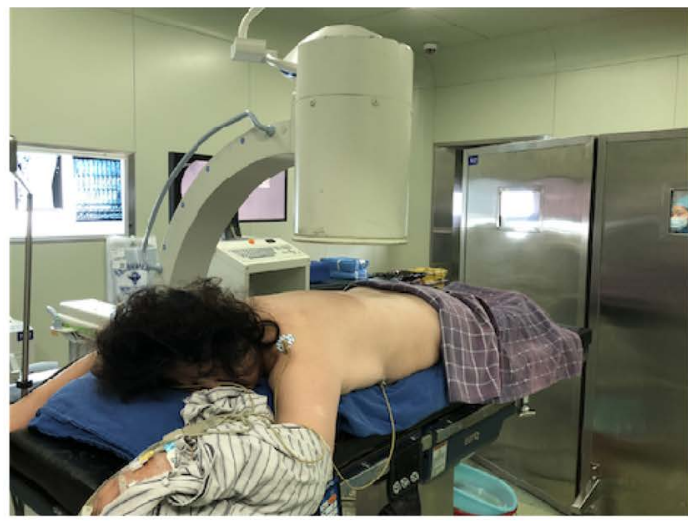

(a)

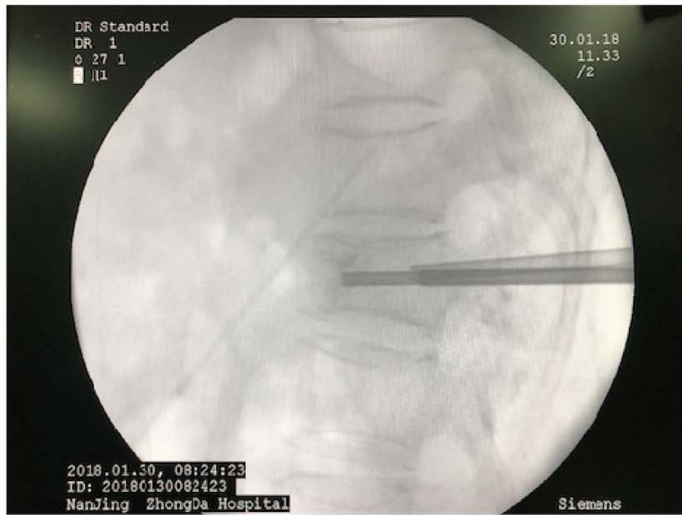

(c)

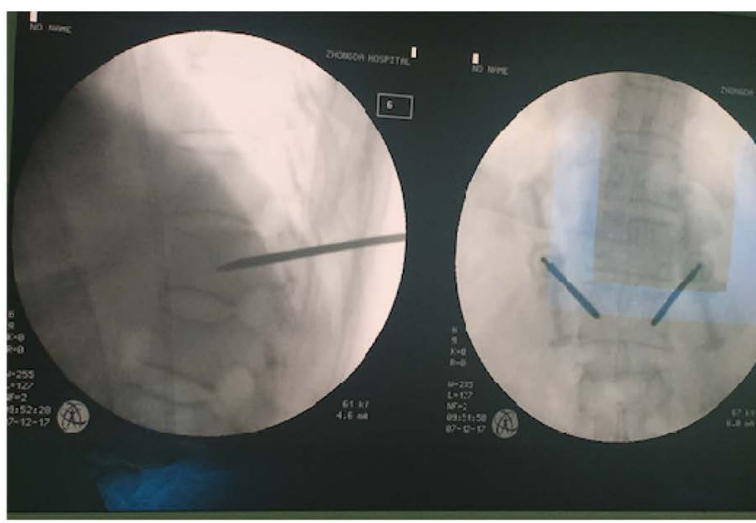

(b)

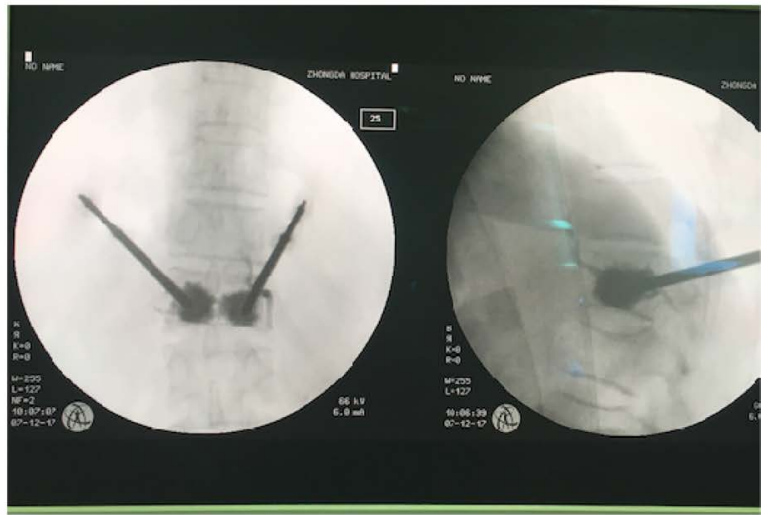

(d)

Figure 4. Surgical steps during percutaneous vertebroplasty (a) Patient Positioning, (b) The pedicle of fractured vertebra localized under biplanar fluoroscopy, (c) Placement of needle up to the anterior and middle one third region of the fractured vertebral body, (d) cement injection into the vertebral body.

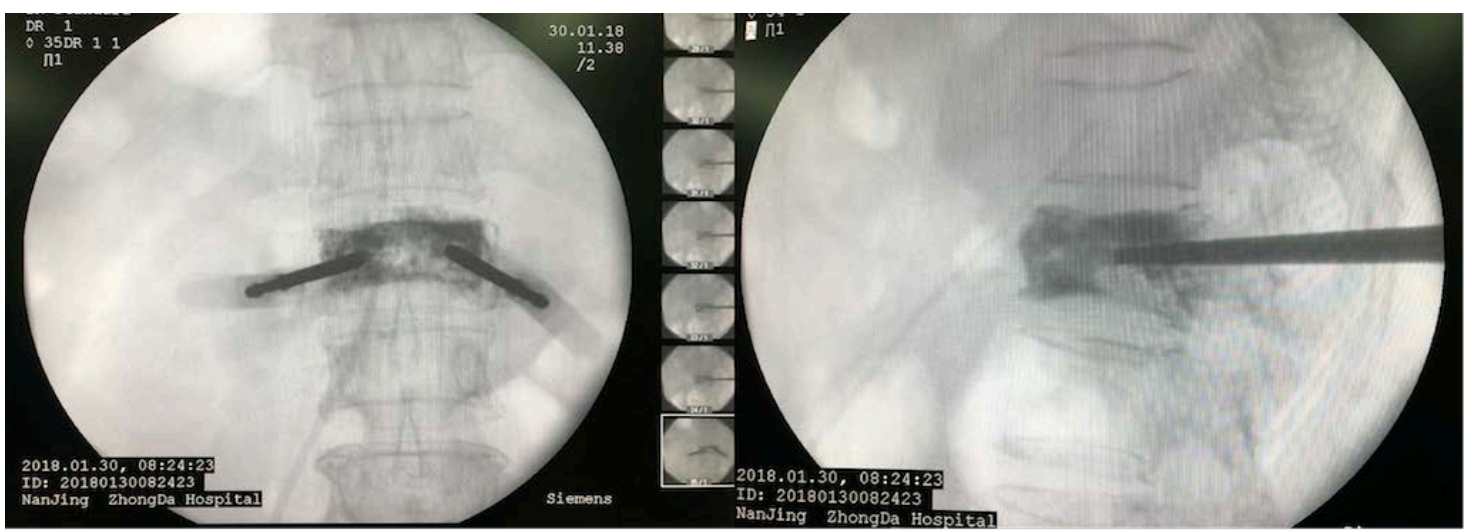

Figure 5. Intraoperative image of fractured vertebra after cement injection. 


\section{Clinical Evaluation}

The fracture free interval of the vertebral body adjacent to the treated vertebra was calculated. Survival analysis was performed using the Kaplan-Meier method.

\subsection{Kaplan-Meier Estimation}

The Kaplan-Meier estimator also called the product limit estimator is known as a non parametric used to estimate the survival function from lifetime data. It is often used to measure the fraction of patients living for a certain amount of time after treatment in medical research [14].

\subsection{Review of Literatures}

The review of various related articles was done focusing on the adjacent vertebral compression fractures in post PVP patients. The search engines like PUBMED, GOOGLE SCHOLAR, EMBRASE and SCOPUS were used to search the articles related to the adjacent vertebral compression fracture in post PVP patients. Around 68 adjacent level vertebral compression fracture articles out of which 57 articles were excluded as the author used balloon kyphoplasty as their mainstay method of treatment. Among 11 reviewed articles due to fewer numbers of patients and due to inadequate data, 2 more articles were excluded.

Percutaneous Vertebroplasty is a safe and effective procedure for alleviating pain and it also allows patients to resume their normal daily life earlier with compared to the conservative management. Till date, there are numerous published data on vertebroplasty in large population of patients [16] [23] [24]. Despite of its beneficial advantages over primary conservative managements, adjacent level vertebral compression fracture remains the challenge for surgeons. Despite the benefits of PVP, there are some complications following surgery: Hematoma, Infection, Adjacent vertebral fracture, neurological deficit. The aim of this review is more concerned on adjacent vertebral fracture, so there is more focus on it.

A study done in 2004 by S. H. Kim, H. S. Kang et al. [15] on 106 patients in with 212 percutaneous vertebroplasties in a period of 3 years (Table 2). They analysed five superior vertebrae and inferior to the treated vertebra. Seventy-two (7.9\%) new fractures were found with the Kaplan-Meier estimate of the 1-year fracture-free rate $93.1 \%$.

For evaluation of risk factors and the development of new symptomatic OVCFs after PVPs, Wan Soo Lee et al. [16] performed a retrospective study from September 1999 to December 2001 (Table 2). A total of 244 cases of PVP for symptomatic OVCFs at 382 levels was performed. Overall, 38 among 244 treated patients (15.6\%) had experienced newly developed symptomatic OVCF(s) during the follow up period. The Kaplan-Meier estimate of the 1-year fracture-free rate was $92.2 \%$.

A.T Trout et al. [17] in year 2006 (Table 2) performed a retrospective analysis calculating the risks and timing of adjacent vertebral compression fractures after 
Table 2. Studies done related to adjacent vertebral fracture following PVP surgery.

\begin{tabular}{|c|c|c|c|}
\hline Author & Study Year & NO. OF CASES & Findings \\
\hline $\begin{array}{l}\text { S. H. Kim, H. S. } \\
\text { Kang et al. [15] }\end{array}$ & 2004 & $\begin{array}{c}106 \text { ( } 14 \text { male, } 92 \\
\text { females, mean age } \\
71.9 \text { yrs })\end{array}$ & $\begin{array}{c}\text { 7.9\% (72) new fractures; Kaplan } \\
\text { Meier Estimate } 93.1 \% \text { fracture } \\
\text { free rate }\end{array}$ \\
\hline $\begin{array}{l}\text { Wan Soo Lee } \\
\text { et al. }[16]\end{array}$ & 2006 & $\begin{array}{c}244(37 \text { male, } 207 \\
\text { females, mean age } \\
66.4 \text { yrs })\end{array}$ & $\begin{array}{l}15.6 \%(38) \text { new } \\
\text { fractures; kaplanmeierest- } 84.4 \% \\
\text { fracture free rate }\end{array}$ \\
\hline $\begin{array}{l}\text { A. T. Trout, D. F. } \\
\text { Kallmes [17] }\end{array}$ & 2006 & $\begin{array}{c}86(28 \text { male, } 58 \\
\text { females, mean age } \\
72.5 \mathrm{yrs})\end{array}$ & $19.9 \%$ (86) new fractures; \\
\hline Kang Lu et al. [18] & 2012 & $\begin{array}{c}157 \text { ( } 24 \text { male, } 131 \\
\text { females, mean age } \\
73.3 \text { yrs })\end{array}$ & $27.7 \%$ (43) new fractures; \\
\hline $\begin{array}{l}\text { Kyung-Ah Lee } \\
\quad \text { et al. [19] }\end{array}$ & 2011 & $\begin{array}{c}188 \text { (25 male, } 163 \\
\text { females, mean age } \\
70.9 \mathrm{yrs})\end{array}$ & $10.3 \%$ (36) new fractures; \\
\hline $\begin{array}{c}\text { Young-Joon Rho } \\
\text { et al. }[8]\end{array}$ & 2011 & $\begin{array}{l}147 \text { (45 male, } 102 \\
\text { females, mean age } \\
70 \text { yrs })\end{array}$ & $\begin{array}{c}18.4 \%(27) \text { new } \\
\text { fractures;kaplanmeierest-85.0\% }\end{array}$ \\
\hline $\begin{array}{l}\text { Myung-Ho Kim } \\
\text { et al. [20] }\end{array}$ & 2011 & $\begin{array}{c}104 \text { ( } 21 \text { male, } 83 \\
\text { females, mean age } \\
71.3 \text { yrs })\end{array}$ & $\begin{array}{c}51.9 \%(54) \text { new adjacent } \\
\text { fractures }\end{array}$ \\
\hline $\begin{array}{l}\text { Ying-Chou Sun } \\
\quad \text { et al. [21] }\end{array}$ & 2011 & $\begin{array}{l}98 \text { ( } 29 \text { male, } 69 \\
\text { females, mean } \\
\text { age } 75.6 \text { yrs })\end{array}$ & $25 \%(41)$ new adjacent fractures \\
\hline $\begin{array}{l}\text { Wen-Jer Chen } \\
\text { et al. [22] }\end{array}$ & 2008 & $\begin{array}{c}106 \text { ( } 19 \text { male, } 87 \\
\text { females, mean age } \\
73 \mathrm{yrs})\end{array}$ & $\begin{array}{l}18.9 \%(22) \text { new } \\
\text { adjacent fractures. }\end{array}$ \\
\hline
\end{tabular}

PVP. A total of 432 patients were included, out of which Seventy-seven (41.4\%) adjacent vertebral fractures were noted in patients with previously treated with vertebroplasty. The median time to diagnosis of an incident adjacent-level fracture was 55.0 days

A retrospective cohort study done by Kang Lu et al. [18] between January 2007 and December 2008 (Table 2). Forty-three (27.7\%) of the 155 patients had subsequent vertebral compression fractures within 2 years of percutaneous vertebroplasty.

A study performed by Wen-Jer Chen et al. [22] in year 2008 (Table 2) showed $18.9 \%$ (22) new adjacent vertebral fractures out of 106 patients previously treated with PVP. This study revealed that the Cement leakage outside the vertebral body during vertebroplasty is one of the complications for adjacent vertebral fractures and is usually clinically asymptomatic.

Young-Joon Rho et al. [8] in a retrospective analysis, in year 2011 (Table 2) found out that out of 147 patients treated with pvp, 18.4\% (27 patients) had adjacent level vertebral compression fractures. The Kaplan meier1-yearfracture 
free interval of this study is $85.0 \%$.

In 2011, Ying Chou Sun et al. [21] performed a study showing correlation between the morphological extent of bone cement during vertebroplasty with the adjacent level vertebral compression fracture after PVP (Table 2). This study showed out of 162 vertebras treated with pvp, 25\% (41) new symptomatic adjacent vertebral fractures were noted. The mean interval between the vertebroplasty and the earliest radiographic demonstration of adjacent vertebral fracture was $134 \pm 225$ days (median 24 days, range 2 - 1038 days). 53\% of these adjacent fractures were seen within 1 month after vertebroplasty. About $86 \%$ were found within 1 year, and 96\% within 18 months after vertebroplasty.

A retrospective study in 2011 (Table 2) done by Myung-Ho Kim et al. [20] showed that out of 104 post pvp patients , 51.9\% (54) adjacent vertebral compression fracture were seen within 1 year follow up. In this analysis, Age of the patient, lumbar lordotic angle, sacral slope, pelvic tilt, pelvic incidence, bone mineral density (BMD), preexisting fracture, and intradiscal cement leakage were recorded for all 104 study subjects.

Kyung-Ah Lee et al. [19] found new adjacent fractures in 36 (10.3\%) out of 351 patients after vertebroplasty surgery in follow up mean time of 6.8 months (range 1 - 47 months) (Table 2).

\section{Discussion}

Adjacent level vertebral compression fracture following percutaneous vertebroplasty using PMMA cement has been reported as a complication [12] [16] [25] [26]. It may be because of additional stress on the adjacent vertebra due to the cement augmentation [27]. Re-collapse or re-fracture of the same vertebral body after PVP has been reported rarely [28] [29].

Numerous risk factors have been reported for the occurrence of new adjacent VCFs after PVP, including growing age, previous vertebral fractures [16], steroids [30], vertebroplasty at the TL junction [15], low bone mineral density, proximity to the initial fracture site cement leakage into the discs [12] and vacuum clefts within the compression fracture [31].

Cement leakage is one of the mostly encountered complications after percutaneous vertebroplasty. Cement leakage outside the vertebral body during vertebroplasty is one of the reasons for adjacent level vertebral fracture and is usually clinically asymptomatic. However, painful new fractures of adjacent vertebral bodies often occur after PV in our clinical practice, especially in those with cement leakage into a disk [22] [32].

In one study [19] they found Intradiscal cement leakage in 91 (25.9\%) of the 351 treated vertebral levels. Those having intradiscal cement leakage, they found new adjacent vertebral compression fractures in 10 of 91 (11\%) levels. In intradiscal cement leakage they found 26 of 260 (10\%) levels new adjacent vertebral fracture. They suggested there is correlation between incidence of new adjacent fracture and intradiscal cement leakage; but not significant $(\mathrm{p}=0.789)$. 
Bone mineral densitometry (BMD) is used to estimate the patient's risk of fracture. It is a measurement of the amount of minerals (mostly calcium and phosphorous) contained in a certain volume of bone. Bone mineral density measurements are used to diagnose osteoporosis. Lower the bone mineral density, higher the chances of adjacent vertebral compression fractures [18]. BMD is measured using dual energy $\mathrm{x}$-rays (DEXA). In one study only the T-score of bone mineral density was significantly associated with subsequent vertebral compression fractures $(\mathrm{p}<0.0001$; odds ratio $=0.27 ; 95 \%$ confidence interval, $0.15-0.49)[19]$.

\section{Conclusion}

Percutaneous vertebroplasty is a safe and efficient procedure for treating osteoporotic vertebral compression fractures. But as we all know, every procedure has some complications. Adjacent vertebral fracture remains one of them. The multiple level osteoporotic vertebral compression fractures and the increasing age of the patients are directly proportional to the risk of developing new symptomatic adjacent vertebral compression fracture after PVP. Moreover, low BMD and cement leakage are other factors that directly affect the incidence of new symptomatic adjacent vertebral fracture.

\section{Conflict of Interest}

None.

\section{References}

[1] Dervis, E. (2005) Oral Implications of Osteoporosis. Oral Surgery, Oral Medicine, Oral Pathology, Oral Radiology and Endodontics, 100, 349-356. https://doi.org/10.1016/j.tripleo.2005.04.010

[2] (2014) Handout on Health: Osteoporosis.

[3] Organization, W.H. (2003) Prevention and Management of Osteoporosis: Report of a WHO Scientific Group. World Health Organization.

[4] Johnell, O. and Kanis, J. (2006) An Estimate of the Worldwide Prevalence and Disability Associated with Osteoporotic Fractures. Osteoporosis International, 17, 1726-1733. https://doi.org/10.1007/s00198-006-0172-4

[5] Kim, S.W. and Chung, Y.K. (2000) Long Term Follow-Up of Osteoporotic Vertebral Fractures according to the Morphologic Analysis of Fracture Pattern. Journal of Korean Society of Spine Surgery, 7, 611-617.

[6] Voormolen, M., et al. (2007) Percutaneous Vertebroplasty Compared with Optimal Pain Medication Treatment: Short-Term Clinical Outcome of Patients with Subacute or Chronic Painful Osteoporotic Vertebral Compression Fractures. The VERTOS Study. American Journal of Neuroradiology, 28, 555-560.

[7] Netter, F.H. (2014) Back and Spinal Cord. Atlas of Human Anatomy.

[8] Rho, Y.-J., Choe, W.J. and Chun, Y.I. (2012) Risk Factors Predicting the New Symptomatic Vertebral Compression Fractures after Percutaneous Vertebroplasty or Kyphoplasty. European Spine Journal, 21, 905-911.

https://doi.org/10.1007/s00586-011-2099-5 
[9] Voormolen, M.H., et al. (2006) The Risk of New Osteoporotic Vertebral Compression Fractures in the Year after Percutaneous Vertebroplasty. Journal of Vascular and Interventional Radiology, 17, 71-76. https://doi.org/10.1097/01.RVI.0000190910.43602.3C

[10] Galibert, P., et al. (1987) Preliminary Note on the Treatment of Vertebral Angioma by Percutaneous Acrylic Vertebroplasty. Neuro-Chirurgie, 33, 166-168.

[11] Allegretti, L., et al. (2014) Intra-Operative Vertebroplasty Combined with Posterior Cord Decompression: A Report of Twelve Cases. Interventional Neuroradiology, 20, 583-590. https://doi.org/10.15274/INR-2014-10019

[12] Uppin, A.A., et al. (2003) Occurrence of New Vertebral Body Fracture after Percutaneous Vertebroplasty in Patients with Osteoporosis. Radiology, 226, 119-124. https://doi.org/10.1148/radiol.2261011911

[13] Kallmes, D.F. and Jensen, M.E. (2003) Percutaneous Vertebroplasty. Radiology, 229, 27-36. https://doi.org/10.1148/radiol.2291020222

[14] Kaplan, E.L. and Meier, P. (1958) Nonparametric Estimation from Incomplete Observations. Journal of the American Statistical Association, 53, 457-481. https://doi.org/10.1080/01621459.1958.10501452

[15] Kim, S., et al. (2004) Risk Factors of New Compression Fractures in Adjacent Vertebrae after Percutaneous Vertebroplasty. Acta Radiologica, 45, 440-445. https://doi.org/10.1080/02841850410005615

[16] Lee, W.S., et al. (2006) Risk Factors of Developing New Symptomatic Vertebral Compression Fractures after Percutaneous Vertebroplasty in Osteoporotic Patients. European Spine Journal, 15, 1777-1783. https://doi.org/10.1007/s00586-006-0151-7

[17] Trout, A.T., Kallmes, D.F. and Kaufmann, T.J. (2006) New Fractures after Vertebroplasty: Adjacent Fractures Occur Significantly Sooner. American Journal of Neuroradiology, 27, 217-223.

[18] Lu, K., et al. (2012) Risk Factors of Subsequent Vertebral Compression Fractures after Vertebroplasty. Pain Medicine, 13, 376-382. https://doi.org/10.1111/j.1526-4637.2011.01297.x

[19] Lee, K.-A., et al. (2011) Analysis of Adjacent Fracture after Percutaneous Vertebroplasty: Does Intradiscal Cement Leakage Really Increase the Risk of Adjacent Vertebral Fracture? Skeletal Radiology, 40, 1537-1542. https://doi.org/10.1007/s00256-011-1139-x

[20] Kim, M.-H., et al. (2011) Risk Factors of New Compression Fractures in Adjacent Vertebrae after Percutaneous Vertebroplasty. Asian Spine Journal, 5, 180-187. https://doi.org/10.4184/asj.2011.5.3.180

[21] Sun, Y.-C., et al. (2011) Risk of Post-Vertebroplasty Fracture in Adjacent Vertebral Bodies Appears Correlated with the Morphologic Extent of Bone Cement. Journal of the Chinese Medical Association, 74, 357-362. https://doi.org/10.1016/j.jcma.2011.06.008

[22] Chen, W.-J., et al. (2010) Impact of Cement Leakage into Disks on the Development of Adjacent Vertebral Compression Fractures. Clinical Spine Surgery, 23, 35-39.

[23] Garfin, S.R., Yuan, H.A. and Reiley, M.A. (2001) New Technologies in Spine: Kyphoplasty and Vertebroplasty for the Treatment of Painful Osteoporotic Compression Fractures. Spine, 26, 1511-1515. https://doi.org/10.1097/00007632-200107150-00002

[24] Peh, W.C., Gilula, L.A. and Peck, D.D. (2002) Percutaneous Vertebroplasty for Severe Osteoporotic Vertebral Body Compression Fractures. Radiology, 223, 121-126. 
https://doi.org/10.1148/radiol.2231010234

[25] Fribourg, D., et al. (2004) Incidence of Subsequent Vertebral Fracture after Kyphoplasty. Spine, 29, 2270-2276. https://doi.org/10.1097/01.brs.0000142469.41565.2a

[26] Komemushi, A., et al. (2006) Percutaneous Vertebroplasty for Osteoporotic Compression Fracture: Multivariate Study of Predictors of New Vertebral Body Fracture. Cardiovascular and Interventional Radiology, 29, 580-585. https://doi.org/10.1007/s00270-005-0138-5

[27] Berlemann, U., et al. (2002) Adjacent Vertebral Failure after Vertebroplasty: A Biomechanical Investigation. Bone \& Joint Journal, 84, 748-752. https://doi.org/10.1302/0301-620X.84B5.0840748

[28] Leslie-Mazwi, T. and Deen, H.G. (2006) Repeated Fracture of a Vertebral Body after Treatment with Balloon Kyphoplasty: Case Illustration. Journal of Neurosurgery. Spine, 4, 270. https://doi.org/10.3171/spi.2006.4.3.270

[29] Wagner, A. and Baskurt, E. (2006) Refracture with Cement Extrusion Following Percutaneous Vertebroplasty of a Large Interbody Cleft. American Journal of Neuroradiology, 27, 230-231.

[30] Hiwatashi, A. and Westesson, P. (2007) Patients with Osteoporosis on Steroid Medication Tend to Sustain Subsequent Fractures. American Journal of Neuroradiology, 28, 1055-1057. https://doi.org/10.3174/ajnr.A0519

[31] Lin, C., et al. (2007) New Symptomatic Compression Fracture after Percutaneous Vertebroplasty at the Thoracolumbar Junction. American Journal of Neuroradiolo$g y, 28,1042-1045$. https://doi.org/10.3174/ajnr.A0520

[32] Lin, E.P., et al. (2004) Vertebroplasty: Cement Leakage into the Disc Increases the Risk of New Fracture of Adjacent Vertebral Body. American Journal of Neuroradiology, 25, 175-180.

\author{
Abbreviations \\ PVP: Percutaneous Vertebroplasty \\ OVCF: Osteoporotic Vertebral Compression Fracture \\ VCFs: Vertebral Compression Fractures \\ PMMA: Polymethylmethacrylate \\ BMD: Bone Mineral Density \\ DEXA: Dual Emission X-ray Absorptiometry
}

